\section{The QOF, NICE, and depression}

I feel I must raise my head above the parapet. I was a member of the mental health group that helped develop the indicators for the depression QOF. There, I have admitted it!

Professor Toop ${ }^{1}$ has made several errors that need correcting.

The first two depression indicators (DEP1 and DEP2) were introduced in 2006, after the publication of the NICE guidelines (CG23) on depression. The indicator (DEP1) was introduced because depression is more common in people with diabetes and heart disease, $^{2}$ that the effect of the comorbid mental health conditions significantly effects outcomes and resource utilisation, ${ }^{2}$ and that effective treatments are available. ${ }^{2}$ Not to have incentivised GPs to identify a group of people who were more at risk clinically, using more health resources, and could be offered an effective intervention, would have been negligent.

There are three NICE guidelines (CG90, CG91, CG123) that recommend questionnaires to support the assessment of the patient, and are not used in a single reductionist approach to decision making.

Studies that showed that GPs don't like using the questionnaires also showed that patients like the use of questionnaires, they feel as though their symptoms are being taken seriously, and that they can understand their progress over time. The use of questionnaires is seen by patients as beneficial, not intrusive.

If nurses do not feel competent to provide initial support for people who are distressed, and to raise questions that are appropriate to their care, then that is an issue for their employers to address. Nurses should be competent to ask the questions in the ultra short questionnaires, and on the basis of the patient's response provide initial advice and support.

Professor Toop also failed to mention the development called Improving Access to Psychological Therapies (IAPT). ${ }^{4}$ This is £0.7 billion development in England that recruits and trains therapists to deliver psychological care. The programme also draws on the NICE guidelines on depression and has pioneered the routine use of the PHQ-9 and the GAD-7 at every contact the patient has with the therapist.

Taken together, the development of QOF domains for depression and the development of the IAPT programme, represent a whole system approach to a condition that is debilitating, common, and costly to the NHS. It seems extraordinary that Toop seeks to undermine this approach with a poorly argued discourse on the use of questionnaires in mental health conditions.

\section{Alan Cohen,}

FRCGP, Director of Primary Care, West

London Mental Health Trust.

E-mail: doctoralancohename.com

\section{REFERENCES}

1. Toop L. The QOF, NICE, and depression: a clumsy mechanism that undermines clinical judgement. $\mathrm{Br}$ J Gen Pract 2011; 61(588): 432-433.

2. National Institute for Health and Clinical Excellence. The treatment and management of depression in adults with chronic physical health problems. NICE guideline 91. London: NICE, 2009

http://guidance.nice.org.uk/CG91 laccessed 8 Aug 2011).

3. National Institute for Health and Clinical Excellence. Common mental health disorders: identification and pathways to care. NICE guideline 123. London: NICE, 2011. http://guidance.nice.org.uk/CG123 laccessed 8 Aug 2011).

4. Improving Access to Psychological Therapies. http://mww.iapt.nhs.uk/ laccessed 8 Aug 2011).

DOI: 10.3399/bjgp11X593785

\section{GPs at the Deep End and Mike Fitzpatrick}

Two themes have been running in tandem in the BJGP since April, both of which highlight a more fundamental issue within general practice.

The first theme comes from the GPs at the Deep End series. 1,2 This is the appreciation of the need for an intimate knowledge of family backgrounds and for more time during consultations to ascertain and manage the psychosocial components of ill health.

The second theme is the ongoing debate started by Mike Fitzpatrick regarding the involvement of general practice with child protection. ${ }^{3}$ More broadly, this is the debate about the extent to which GPs should be concerned with seeking out an understanding of patients' family/social circumstances compared to just concerning ourselves with the traditionally more narrowly-defined, 'medical symptoms', 4,5

Both themes flag up a fundamental problem with the current biomedical model, in other words, its basis in a Cartesian mind-body split.

The Deep End articles have very clearly shown how the psychosocial aspects of patients' lives are deeply bound up with their illness presentations. I would like to add another theme that brings the problem of a belief in a mind-body split into clear relief, the problem of medically unexplained symptoms (MUS).

These constitute $20-30 \%$ of primary care consultations, and $40-50 \%$ of secondary care consultations ${ }^{6}$ and yet how often do we see MUS featured on medical education programmes?

Although we have very little understanding so far of the underlying mechanisms, we know that there is an association with a history of past trauma and that incidence increases down the social scale. ${ }^{7}$

It is likely that underlying social factors have an impact in aetiology and one could hypothesise that these social factors are being manifested as physical symptoms through the mediation of 'the mind'.

We are still waiting for neuroscience to provide a scientific understanding of mindbody connections, but meanwhile it seems that approaching physical symptoms only in narrowly defined medical terms is missing the very large elephant in the room.

Whether we like it or not, illness is intimately bound up with patients' social lives; once we have the scientific understanding these issues will no longer be subject to debate.

\section{Sian Harris,}

GP, Portslade County Clinic, Old Shoreham Road, Portslade, BN4 1XR.

E-mail: sianharris1964dagmail.com

\section{REFERENCES}

1. Watt $G$. Working with vulnerable families in deprived areas. Br J Gen Pract 2011; 61(581): 298.

2. Sambale P, Mandeville B. The Keppoch Medical Practice: reporting from the Deep End. Br J Gen Pract 2011; 61(588): 463

3. Fizpatrick M. How to protect general practice from child protection. Br J Gen Pract 2011; 61(585): 299.

4. Allister J. How to protect general practice from child protection. BrJ Gen Pract 2011; 61(586): 326.

5. Lang D. How to protect general practice from child protection. Br J Gen Pract 2011; 61(587): 380.

6. Improving Access to Psychological Therapies. Medically unexplained symptoms: positive practice guide. London: Department of Health, 2008

7. Dirkzwager AJ, Verhaak PF. Patients with persistent medically unexplained symptoms in general practice: characteristics and quality of care. BMC Fam Pract 2007; 8: 33.

DOI: 10.3399/bjgp11X593794 